\title{
EXPLOSION PREVENTION IN THE PRESENT CONDITIONS OF PRODUCTION
}

The article solves some questions of possible approaches to explosion prevention in production plants. In the introductory part it deals with thoughts about the safety of personnel in an industrial plant in areas with an explosion danger. Further, it defines individual views of industrial plants and suggests the means of solving the explosion prevention in industry. In the conclusion it recommends an approach to the described questions and the means of ensuring a systematic development in the field of explosion prevention.

\section{Introduction}

In each period of time and in different areas of human activities we ask ourselves a question how to further continue in technical, economic and cultural, or in other development of the society. With our own approach to this question we define our personality to the presented questions in the given sphere, and with our reaction to the question "how to continue" we join working groups that strengthen or weaken the development of human activity.

In a given moment the society always finds itself in a stage that corresponds to a certain degree of scientific knowledge and a level of technical support in the given field. By virtue of its legislative frame it forms larger or smaller possibilities for further development of this knowledge, and as such it forms and shifts itself among the technical elite or vice versa. This process, being permanent and unchangeable whether we like it or not, is also demanding, time consuming and tiring. The further development of industrial production is not possible without a continuously new, modern technical support which shifts the human activity onto a continuously higher level of performance, productivity, economics etc.

This trend sharply collides with human nature; person's feelings and needs mostly require satisfaction, security, peace and well-being. The new period of civilized development must bring the harmony between requirements of people and technical development. A systematic development is not possible without a scientific approach completed with manpower and its high qualification supported by a meaningful research activity.

This approach, ensured through an amount of current information on theoretical and practical basis, must be continuously kept and developed. This continuous development of knowledge and development of industrial production is even connected with such fields as occupational safety during the production process in every sphere of economics. Even in such fields as safety, namely industrial safety, the impacts of technical development can be seen. Just as the technologies are permanently being modernized, also the safety systems and equipment work on the principle of a still higher level of automation.

The safety level in the sphere of documentation, training and publication activities also depends on the entire scientific-research work in this sphere.

How to assess the safety level in industry, namely in the specialization of explosion protection, on a higher level from technical, organizational and economic points of view?

One of the views how to achieve this target is to define the ways of achieving the sub-targets and also the targets as a whole.

It is important to realize the successive way of achieving individual results with a precise definition of the final solution.

At the same time, accepting the individually achieved goals as a continuous and never ending creative activity.

This approach can get us to the front position in a certain field in the form of winning the needed information, an amount of credible details concerning the given questions, current state of knowledge, and individual approach of every person in the scientific or research work, increasing the level of technical solution of the questions. Subsequently, through an interconnection of these individual approaches with a group revision and discussion to form the final complete solution from all viewpoints, ensuring a continuous development of the given field.

This approach leads to an implicit viable solution which is essential to be immediately put in praxis for verification and to draw the feedback about its functionality.

\footnotetext{
* Libor Stroch

VVUU, Ostrava - Radvanice, Czech Republic, E-mail: vvuu@vvuu.cz
} 


\section{Assessment of industrial plant from the viewpoint of explosion protection}

For the sphere of industrial safety with specialization in the explosion prevention the above mentioned can be made concrete into the following recommended working procedure enabling a complex solution.

On the basis of the present knowledge in the field of explosion prevention we can define the subsequent steps leading to ensuring the safety operation.

2.1. Define the industrial plant - technology, production and operational requirements [2]

2.2. Define the matters accompanying the technological process $[3,4]$

2.3. Define the working procedures during a production process and risks assessment [9]

2.4. Perform the Explosion Protection Documentation [1]

2.5. Take over impulses from the practical solution for testing and development $[5,6,7]$

2.6. Examine the causes and reasons for new solutions [8]

\subsection{Define the industrial plant - technology, production and operational requirements}

Production lines and production plants reflect, during their formation, requirements of the manufacturer and they are solved by means of project documentation for the subsequent implementation of a particular plant on a production of the final product. Already in the stage of the project preparation it is necessary to deal with safety questions in the moment when manufactured material is a flammable substance which can form an explosive atmosphere. In such a case it is necessary to consider the explosion prevention. The project organizations must, in accordance with the valid legislation and in cooperation with professional workplaces, define conditions for a safety operation. These conditions refer even to such situations when it comes to changes in technology or its parts, or to changes in the used materials. This activity must be solved through a project change or project modification and the current state must be declared while commissioning.

After this solution we go out from the following initial basis:

- requirements of the technology operator

- technological scheme and production description

- current or created design and technical documentation,

- operational and safety regulation

- detailed data sheets of technology parts

- or data about selected technical parameters.

\subsection{Define the matters accompanying the technological process}

Materials entering the production process, going through the production process and forming final products including waste material must be subjected to a proper analysis and their firetechnical characteristics must be determined. These characteristics further serve as a basis for determining the outside influences according to ČSN inside and outside the technological devices [3] (being applied in the Czech Republic). For quality assessment of materials accompanying the production it is necessary to work with the safety sheets of the assessed matters. The selected parameters are essential for the performance of explosion measures in particular production conditions.

Among the main parameters belong mainly [2]:

- grain size composition of a substance,

- flash, ignition, or glow temperature,

- lower explosibility limit

- maximum explosion pressure,

- pressure increase rate,

- explosibility constant,

- oxygen content limit,

- minimum initiation energy,

- or other parameters according to a concrete assignment.

These characteristics and explosion parameters of substances are part of the created documentation and are documented by provable protocols about their determination. It is appropriate to determine these parameters on the basis of particular tests on a professional workplace so that the values which are further being worked with would have a credible value and would correspond to the current state in the particular plant.

\subsection{Define working procedures during a production process and risks assessment}

Definitions of working procedures in production technological sheets or production plans are necessary for the operator for a safe planning of activities of the production, maintenance, possibly repairs. A detailed analysis of individual steps during the starting of technology, the production process itself, technology shut down, maintenance procedure, check, revision or repairs of individual parts or of the whole technology must be properly assessed so that such organizational measures could be taken, or completed with technical solutions so that the enforced technology could be defined as safe. According to the legal regulation the employer is obliged to create conditions for a safe and healthy environment by means of a suitable organization of safety and operational health protection and by means of taking measures for risks prevention. Risks prevention means all measures resulting from legal and other regulations ensuring the safety and operational health protection and with measures taken by an employer aiming at prevention of risks, their removal or at minimizing the incidence of irremovable risks. In the production process, on the basis of the knowledge of concrete conditions, it is the duty of the employer to search for the risks, to investigate their causes and sources, and to take measures for their removal. When applying the principles of risks prevention or for ensuring the explosion protection, the employer takes the technical and organizational measures, in accordance with legal regulations, adequate to the 
nature of the plant in accordance with the principles applied according to the type of particular activity, in the following order:

- preventing creation of explosive atmosphere,

- preventing initiation of explosive atmosphere,

- decreasing harmful explosion effects so that health and safety of employees would be ensured

Defining and evaluating particular activities in the production process must always be concrete and it is not possible to generalize them. After taking the technical and organizational measures, at minimum these three activities must follow:

- area classification to areas with explosion danger and to areas without explosion danger,

- indication of places with explosion danger with safety labels,

- creation of a written Explosion Protection Documentation and its administration corresponding to the current situation.

With this approach the operator is able to ensure a workable and safe production process with clearly defined requirements for performing operational activities of individual employees in all production parts.

\subsection{Perform the Explosion Protection Documentation}

With the knowledge of the previous points it is possible to come to creation of the complete explosion prevention proposal of a given plant and to create an up-to-date Explosion Protection Documentation according to Directive 1999/92/EC of the European Parliament and of the Council on minimum requirements for improving the safety and health protection of workers potentially at risk from explosive atmospheres. [1].

The Explosion Protection Documentation must contain, at minimum, the following parts of a complex assessment:

a) analysis of used substances occurring in the assessed plants,

b) risk analysis of individual assessed plants and devices - technology and device analysis in the period of starting, shut down, normal operation and expected failures,

c) environment proposal - resulting from the risk analysis,

d) defining the concrete initiation sources,

e) proposal on particular technical measures,

f) proposal of particular organizational measures,

g) coordination duties,

h) administration of documentation and indication of dangerous areas,

i) inspection, checks and trainings.

The operator or by the company authorized person must ensure the updating of this documentation in such a way that a continuous objectiveness should be ensured.

For ensuring the objectiveness it is necessary to perform an update always when:

- it comes to a change or modification of technology and to installation of new equipment and components,

- it comes to a change of used or elaborated substances,
- it comes to a change of operational procedures etc.

Each company or its manager as well as Occupational Safety and Health and Fire Prevention workers must process the outputs and conclusions of the Explosion Protection Documentation technical and organizational measures into internal guidelines, directives, regulations, working procedures, and rules.

The staff of the given plants must be informed about the content of the Explosion Protection Documentation both in a written and oral form. Internal documents must be completed or edited in case of revision of the Explosion Protection Documentation.

\subsection{Take over impulses from the practical solution for testing and development}

Providing that we want to keep the time with the developing engineering in industrial production it is necessary to assess the setting of particular elements or to evaluate the current ways of explosion prevention. To solve possible shortcomings or requirements of the production process through verification of new parameters, through defining modified constructions or an entirely new conception. These solutions should be subjected to a development process ending in verification tests for the confirmation of hypotheses.

It is appropriate to confront the conclusions, achieved through fulfillment of the above mentioned, with similar activities in the field and to evaluate results of different technical solutions. Thus flexibly react to the market needs and in the given period to ensure a standard technical solution that conforms to all the required parameters.

\subsection{Examine the causes and reasons for new solutions}

The process running according to the previous points provokes many thoughts and questions. One of them can be the question of safety versus economics, or complication for technological production procedure and vice versa.

Here it is appropriate to subject such questions to a detailed analysis and in cooperation with research and scientific workplaces to search for correct answers. Thus an assignment for a research task of a concrete form can be created and can join together the power of production, construction, projection, development, and research in one unit. At the end of the effort of such group can be, and often is, a new solution or an entirely new product which shifts the safety further again if it ensures all the required conditions for production.

\section{Conclusion}

Everything already mentioned has been basically known and nothing extra new has been discovered here. This article provides 
a simple, comprehensive suggestion how to proceed in a systematic way during a continuous ensuring of explosion prevention in industrial plants. It answers the question how to secure the safety in plants with explosion danger and how to maintain this safety during the whole operating life of production technology. It defines that the aim of a new striving in explosion prevention is not one solution, measure or protection element but a systematic approach to the questions under a continuous development and solution. Thus the goal of our action is a path guiding us through safe technologies while keeping the technical level of solution corresponding to the stage of knowledge in the given field.
Experience shows that my conclusion is not entirely normally used in praxis and in many cases it hardly gets into the common subconscious of the production workers. Though, responses from praxis prove that the topic of safety has become the topic of the day today and it is becoming priority number one. The witness of which is the modified legislative, constantly better approach of the technical public and the awareness of the companies of these questions. With quality control and enforceability of particular requirements from responsible workers and in companies it is possible, in a foreseeable period, to achieve satisfactory results to which conditions have already been created.

\section{References:}

[1] Directive 1999/92/EC of the European Parliament and of the Council on minimum requirements for improving the safety and health protection of workers potentially at risk from explosive atmospheres.

[2] European Standard EN 1127-1: Explosive Atmospheres - Explosion Prevention and Protection - Part 1: Basic Concepts and Methodology.

[3] ČSN 33 2000-3: Electrical Regulations - Electrical Apparatus. Part 3: Determination of Basic Characteristics. (Contains principles of IEC 364-3:1993)

[4] ČSN EN 61241-10: Electrical apparatus for use in the presence of combustible dust. Part 10: Classification of areas where combustible dusts are or may be present.

[5] EN 14373: Explosion suppression systems.

[6] EN 14491: Dust explosion venting protective systems.

[7] EN 13237: Potentially explosive atmospheres - Terms and definitions for equipment and protective systems intended for use in potentially explosive atmospheres.

[8] EN 12874: Flame arresters - Performance requirement, test methods and limits for use.

[9] EN 1050: Safety of machinery - Principles for risk assessment. 